\title{
Polyhydroxyalkanoate Production Enzymes: a Survey and Biological Perspective
}

\author{
Christopher J. Brighama and Anthony J. Sinskey ${ }^{\mathrm{a}, \mathrm{b}, \mathrm{c}, \mathrm{d} *}$ \\ ${ }^{a}$ Department of Biology, Massachusetts Institute of Technology, \\ Cambridge, MA 02139, USA \\ ${ }^{b}$ Siberian Federal University, \\ 79 Svobodny, Krasnoyarsk, 660041 Russia \\ ${ }^{c}$ Engineering Systems Division, \\ Massachusetts Institute of Technology, \\ Cambridge, MA 02139, USA \\ ${ }^{d}$ Division of Health Sciences Technology, \\ Massachusetts Institute of Technology, \\ Cambridge, MA 02139, USA ${ }^{1}$
}

Received 10.09.2012, received in revised form 17.07.2012, accepted 24.09.2012

Polyhydroxyalkanoates (PHA) have attracted interest as bio-based, biodegradable biocompatible polymers. Researchers have accumulated a wide breadth of knowledge on the biosynthetic processes of these valuable polymers, with experts in the disciplines of microbiology, biochemistry, physics, medicine, and engineering contributing to the current state of knowledge of synthesis, production and application of PHA. An important perspective of PHA biosynthesis is the subset of microbial enzymes that are involved in producing this polymer and their many permutations. In this review, we survey the key enzymes involved in synthesis and homeostasis of all types of PHA. Emphasis is made on structure and function of enzymes and how enzymology has shaped knowledge of the PHA production pathway and ushered in new discoveries.

Keywords: bioplastics, polyhydroxyalkanoate, enzymes, granule associated proteins, polymer biosynthesis, PHA homeostasis.

\section{Introduction}

As natural products, polyhydroxyalkanoates (PHAs) have been intensively studied for over 50 years (Lemoigne, 1927; Merrick et al., 1965; Peoples, Sinskey, 1989a; Anderson et al., 1990;
Valentin, Steinbuchel, 1994). PHAs, as bioplastics with favorable thermal and mechanical properties (Sudesh et al., 2000), have long been thought of as replacements for petroleum-based polymers. Currently, PHAs are under intense investigation

\footnotetext{
Corresponding author E-mail address: asinskey@mit.edu (C) Siberian Federal University. All rights reserved
} 
as biocompatible and biodegradable materials for medical uses, such as resorbable sutures, tissue culture scaffolds, implants, and drug delivery devices (Shishatskaya et al., 2002; Shishatskaya, Volova, 2004; Shishatskaya et al., 2008; Shishatskaya et al., 2009). These biopolymers have also been investigated for household, agricultural, and industrial uses (Philip et al., 2007; Chen, 2009). Researching the production of these polymers, various inexpensive feedstocks, such as agricultural and food processing wastes, have been shown to be attractive as carbon sources. Also, there is a wealth of literature based on the use of gaseous feedstocks containing carbon dioxide $\left(\mathrm{CO}^{2}\right)$ as the main carbon source for polymer production (Volova et al., 1987; Volova et al., 1988a; Volova et al., 1988b; Ishizaki et al., 2001; Volova et al., 2001; Cramm, 2009).

PHAs are divided into three main types, based on monomer composition. Polymers containing monomers with a four- or five-carbon backbone are called short chain length PHAs (sclPHA), and polymers with six- to fourteen-carbon backbone monomers are known as medium chain length (mcl-PHA). Polymers produced with both scl- and mcl-monomers are known as mixed chain length PHAs. Production of over 150 varieties of PHA has been demonstrated to date (Valentin, Steinbuchel, 1994), however only a select few exhibit any usefulness. The organism that has long been considered the paradigm of PHA biosynthesis, Ralstonia eutropha, natively produces scl-PHA. The Pseudomonas species, also well studied in terms of their polymer biosynthesis, typically produces mcl-PHA (Huisman et al., 1989; Timm, Steinbuchel, 1990; Huijberts et al., 1992). Some bacteria, such as Aeromonas caviae, produce mixed chain length PHA (Lee et al., 2000; Fukui, Doi, 1997).

Table 1 lists the main enzymes involved in scl- or mcl-PHA homeostasis. In this review, we discuss the critical enzymological discoveries that have been made over the decades involving each of these enzymes. As a result of the works discussed here, metabolic engineering and directed evolution of the PHA production pathway has become both feasible and adaptable.

Table 1. Survey of key enzymes involved in scl- and mcl-PHA homeostasis and their biochemical characterization.

\begin{tabular}{|c|c|c|}
\hline Enzyme & Known in vitro assay & Assay reference \\
\hline PhaA - $\beta$-ketothiolase & $\mathrm{Y}$ & (Peoples, Sinskey, 1989b) \\
\hline PhaB - Acetoacetyl-CoA reductase & $\mathrm{Y}$ & $\begin{array}{l}\text { (Peoples, Sinskey, 1989b; Budde et al., } \\
\text { 2010) }\end{array}$ \\
\hline PhaJ - $(R)$-specific enoyl-CoA hydratase & $\mathrm{Y}$ & (Tsuge et al., 2003) \\
\hline $\begin{array}{l}\text { PhaG - }(R) \text {-3-hydroxydecanoyl-ACP:CoA } \\
\text { transacylase }\end{array}$ & $\mathrm{N}$ & None \\
\hline PhaC - PHA synthase & Y & (Yuan et al., 2001) \\
\hline iPhaZ - Intracellular PHA depolymerase & $\mathrm{Y}^{*}$ & $\begin{array}{l}\text { (Gebauer Jendrossek, 2006; Uchino, Saito, } \\
\text { 2006; } \\
\text { Uchino et al., 2007) }\end{array}$ \\
\hline ePhaZ - Extracellular PHA depolymerase & $\mathrm{Y}$ & (Gebauer, Jendrossek, 2006) \\
\hline
\end{tabular}

*See text. Assay methods for PHB thiolysis and hydrolysis have been developed. However, a method has not yet been established for separating out individual iPhaZ enzyme activities and determining whether hydrolysis or thiolysis or both occur in vivo. 


\section{Polyhydroxyalkanoate biosynthesis}

We know the value of PHA in several applications, as stated above, but why do cells natively synthesize the polymer? Typically, PHA is biosynthesized by microorganisms in response to nutrient (non-carbon) limitation. The polymer represents intracellular storage of carbon and reducing potential in many organisms (Anderson, Dawes, 1990; Brigham et al., 2011). Bacteria store PHA in intracellular inclusion bodies known as granules (Fig. 1), with the best-studied example being that of $R$. eutropha. Recently, it has been demonstrated that polyhydroxybutyrate (PHB) synthesis in $R$. eutropha is dependent on the stringent response (Brigham et al., manuscript submitted), further emphasizing the role of PHA in stress response. Also it has been demonstrated that $R$. eutropha cells containing intracellular stores of PHB are capable of withstanding other stress conditions, such as temperature and $\mathrm{pH}$ challenges (N. Zhila, T.G. Volova, personal communication).

It has been demonstrated that many different bacteria, as well as some archaea, can synthesize PHA. The most well-known examples are mentioned above, but many other species have been shown to synthesize intracellular polymer, while examination genome sequences of many other organisms suggests PHA biosynthesis capabilities. Some, in the case of Legionella pneumophila, potentially use PHB as a mechanism of persistence in nutrientpoor environments prior to infection of a host organism (Mauchline et al., 1992). This rationale could be suggested in the case of Vibrio cholerae,

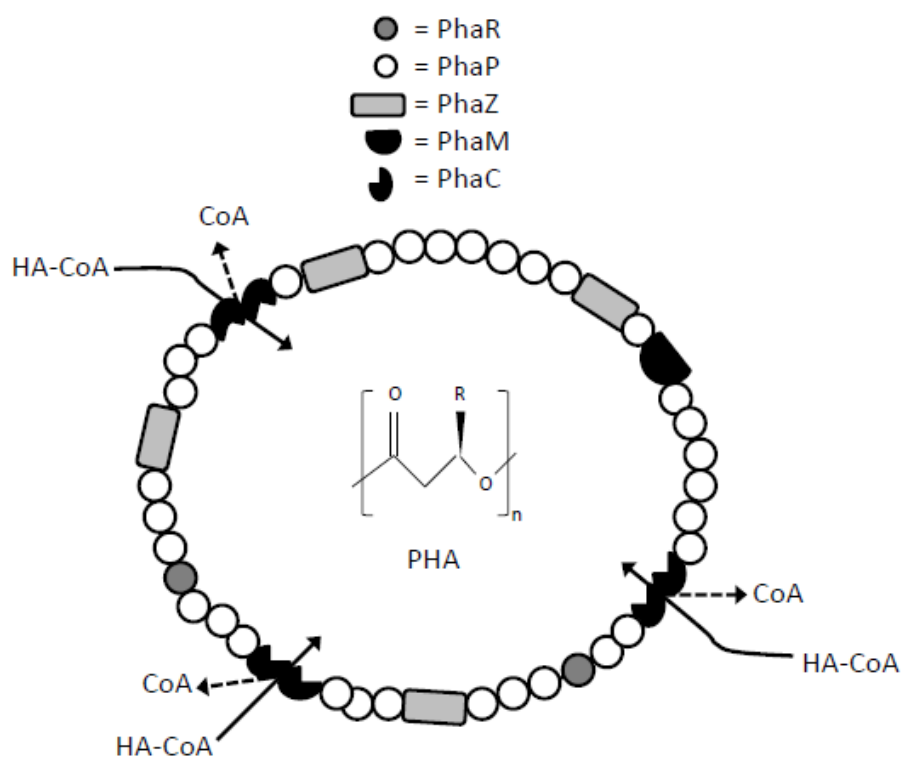

Fig. 1. Schematic drawing of an intracellular polyhydroxyalkanoate (PHA) granule. The granule, an intracellular inclusion that is sometimes considered an organelle, is surrounded by proteins and enzymes with various roles in PHA homeostasis. The phasin (PhaP) protein segregates the hydrophobic PHA from the aqueous cytoplasm (Potter et al., 2004). The regulator (PhaR) binds to PHA and/or phaPl promoter DNA and regulates phasin expression. The PhaM protein is thought to anchor the PHA granule non-specifically to the nucleoid (Pfeiffer et al., 2011). The depolymerases (PhaZ) mobilize PHA during nutrient excess and carbon starvation (Jendrossek, Handrick, 2002; York et al., 2003). The PHA synthases (PhaC) polymerize PHA, using hydroxyacyl-CoA (HA$\mathrm{CoA}$ ) molecules as monomers, resulting in the addition of an HA monomer to the nascent PHA chain and the release of a CoA moiety (Yuan et al., 2001; Cho et al., 2012) 
the genome of which contains genes for PHA biosynthetic machinery. Regardless of what genus or species of microorganism synthesizes the polymer, the function of PHA in the cell is as a response to environmental stresses. This and the potential commercial value of different types of PHA make the polymer an interesting topic for study.

\section{Monomer supply}

Monomers for PHA biosynthesis are typically produced in one of three ways: 1) they are synthesized de novo from compounds like acetyl-CoA and propionyl-CoA, 2) the CoA thioesters present as intracellular intermediates of fatty acid degradation ( $\beta$-oxidation) are converted to $(R)$-3-hydroxyacyl-CoA compounds for use as PHA substrates (Tsuge et al., 2000), or 3) hydroxyacyl-ACP (acyl carrier protein) conjugates are converted to ( $R$ )-3-hydroxyacylCoA molecules for use as PHA polymerization substrates (Hoffmann et al., 2000). Figure 2 shows an example PHA production pathway combining all monomer supply pathways discussed here. Method (1) above is performed by microorganisms that produce mainly scl-PHA, such as R. eutropha. Methods (2) and (3) are performed by organisms that produce mcl-PHA, like Pseudomonas species (Lageveen et al., 1988; Hoffmann et al., 2000; Chung et al., 2009).

For synthesis of short chain PHA precursors, two molecules of acetyl-CoA, or one molecule of acetyl-CoA and one molecule of propionyl-CoA, are ligated together by a $\beta$-ketothiolase enzyme

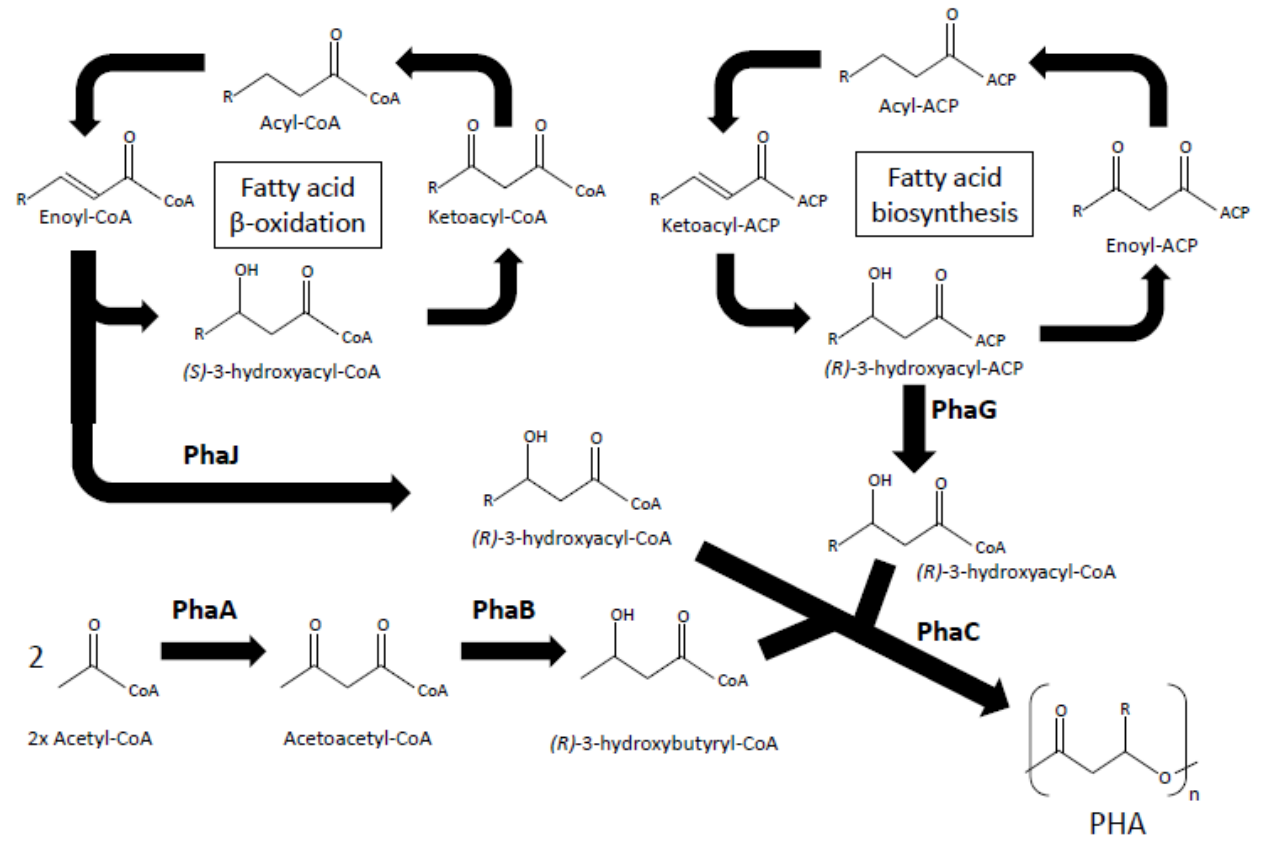

Fig. 2. Pathway diagram of PHA biosynthesis including the three routes of monomer supply discussed in this review. Medium chain length PHA (mcl-PHA) can be produced with monomers supplied from fatty acid $\beta$-oxidation (via the PhaJ enzyme (Fukui et al., 1998)) or fatty acid biosynthesis (via the PhaG enzyme (Rehm et al., 1998)). Traditional PHB production, as demonstrated in wild type Ralstonia eutropha, is supplied with monomers that are produced by the PhaA and PhaB enzymes, where two molecules of acetyl-CoA are ligated together (PhaA) to form acetoacetyl-CoA and then reduced (PhaB) to produce the 3-hydroxybutyryl-CoA precursor (Peoples, Sinskey, 1989b) 
to produce 3-hydroxybutyryl-CoA (3HB-CoA) or 3-hydroxyvaleryl-CoA (3HV-CoA), respectively. The acetyl-CoA typically comes from carbon flow through central metabolism from the Entner-Doudoroff pathway. Propionyl-CoA results from the breakdown of odd carbon chain length fatty acids during $\beta$-oxidation; typically propionate is added to the bacterial culture to foster the production of 3-hydroxyvalerate (3HV) monomers in PHA. Other short chain length precursors of PHA include lactyl-CoA (LA-CoA) and 3-hydroxypropionyl-CoA (3HPCoA). The LA-CoA precursors are typically produced by the ligation of a CoA moiety onto lactate from acetyl-CoA, using a CoA transferase enzyme (Matsumoto, Taguchi, 2010). Synthesis of lactate-containing polymers has not been demonstrated by wild-type organisms. 3HP-CoA can be produced in engineered organisms from glycerol (Andreessen et al., 2010; Andreessen, Steinbuchel, 2010), 3-hydroxypropionaldehyde, malonyl-CoA, or degradation intermediates of 1,7-heptanediol or 1,5-pentanediol (Andreessen et al., 2010), and from wild-type organisms by direct feeding of 3-hydroxypropionate to the growth media (Hiramatsu, Doi, 1993).

For synthesis of long chain monomers, intermediates of fatty acid degradation or fatty acid biosynthesis can be exploited. Intermediates from fatty acid $\beta$-oxidation, specifically trans2-enoyl-CoA compounds, are substrates of an $(R)$-specific enoyl-CoA hydratase enzyme (PhaJ), which will convert the substrate into a PHA precursor (Tsuge et al., 2000). The exact length of the 3-hydroxyacyl-CoA (3HA-CoA) precursor produced depends on the length of the starting enoyl-CoA compound ( $\mathrm{Li}$ et al., 2011; Wang et al., 2011). PHA precursor molecules can also be synthesized via fatty acid biosynthesis. It was demonstrated that Pseudomonas aeruginosa and Pseudomonas putida strains could produce mcl-PHA when grown on non- related carbon sources, i.e. gluconate. An (R)-3hydroxydecanoyl-ACP:CoA transacylase, PhaG, was shown to convert a fatty acid biosynthesis precursor, specifically 3-hydroxyacyl-ACP, into (R)-3-hydroxyacyl-CoA molecules for PHA biosynthesis (Hoffmann et al., 2000).

\section{PhaA and BktB,}

\section{$\beta$-ketothiolase enzymes}

Reaction: $2 \times$ acetyl-CoA $\rightarrow$ acetoacetyl-CoA (PhaA and BktB), or acetyl-CoA + propionyl$\mathrm{CoA} \rightarrow \beta$-ketovaleryl-CoA

The $\beta$-ketothiolase enzymes produce monomers for scl-PHA. These enzymes perform "bio-Claisen" condensations on two CoA thioester molecules, thus creating a carbon-carbon bond (Masamune et al., 1989a; Masamune et al., 1989b). Masamune, Sinskey, and coworkers presented the first characterized $\beta$-ketothiolase from Zoogloea ramigera (Davis et al., 1987a; Davis et al., 1987b; Peoples et al., 1987). Through further examination using a point mutant $\beta$-ketothiolase enzyme, it was determined that a cysteine residue at position 89 (C89) was a critical active site nucleophile (Thompson et al., 1989). A gene encoding a similar enzyme, termed phbA (now known as phaA), was characterized in $R$. eutropha, using the $Z$. ramigera sequence as a seed. In the R. eutropha primary protein sequence, a highly conserved cysteine residue analogous to C89 was found, as well as a conserved cysteine residue towards the $C$-terminal end of the protein (Peoples, Sinskey, 1989b). This residue, C378, has been determined to be an active site base involved in deprotonation during the condensation reaction (Masamune et al., 1989a; Masamune et al., 1989b). The importance of C378 was further confirmed by site-directed mutagenesis in $Z$. ramigera (Palmer et al., 1991).

Slater and coworkers (1998) established the presence of multiple $\beta$-ketothiolase paralogs in $R$. eutropha. PhaA was found to catalyze only 
the production of $3 \mathrm{HB}-\mathrm{CoA}$. Another enzyme, $\mathrm{BktB}$, catalyzes the production of $3 \mathrm{HB}-\mathrm{CoA}$ or 3HV-CoA. The examination of thiolytic cleavage activities (the reverse reaction) of PhaA and BktB show that PhaA is specific to production (or cleavage, in vitro) of $\mathrm{C} 4 \mathrm{PHA}$ precursors like 3HB-CoA, whereas BktB has broader specificity and can produce PHA precursors of $\mathrm{C} 4-\mathrm{C} 6$ chain length (Slater et al., 1998). Recently, the presence of 13 other isozymes of PhaA has been examined in R. eutropha.

Expression of only 5 of the 15 total isozymes was detected under PHB production conditions. Surprisingly, deletion of 8 of the 15 genes encoding PhaA isozymes (including phaA and $b k t B$ ) was required to significantly decrease the intracellular PHB content in R. eutropha, suggesting that the analogous activities of other enzymes could at least partially substitute for the lack of PhaA activity in PHB production (Lindenkamp et al., 2010).

\section{PhaB, reductase enzymes}

Reaction: acetoacetyl-CoA $+\mathrm{NADPH} \rightarrow$ 3-hydroxybutyryl-CoA $+N A D P^{+}$

The enzyme acetoacetyl-CoA reductase is typically termed $\mathrm{PhaB}$, in most organisms. Acetoacetyl-CoA reductase activity was measured in bacterial cell extracts as early as 1969 (Bloomfield et al., 1969). This enzyme was first purified from extracts of Azotobacter biejerinckii. Reductase activity of this purified enzyme preferentially used NADPH as the cofactor, and reduction proceeded optimally at a pH of $\sim 5$ (Ritchie et al., 1971). NADPH-linked acetoacetyl-CoA reductase activity was also shown in Zoogloea ramigera (Saito et al., 1977). The PhaB1 gene product from R. eutropha $\mathrm{H} 16$ also exhibited NADPH-dependent reductase activity (Peoples, Sinskey, 1989b). The genes phaA and $p h a B$ from the methylotrophic bacterium Paracoccus denitrificans were analyzed in recombinant $E$. coli. It was shown that NADH was preferred over NADPH for recombinant P. denitrificans PhaB activity (Yabutani et al., 1995). A PhaB homolog was characterized in the haloarchaeon Haloarcula hispanica (Han et al., 2009), suggesting the presence of PHA production pathways in another domain of life besides bacteria.

In $R$. eutropha, additional phaB genes and their respective products have been characterized. Deletion of phaBl (present in the phaCAB operon in R. eutropha) and phaB3 resulted in a decreased ability to produce intracellular PHB. Deletion of a gene termed phaB2, however, did not result in any observable phenotype. In addition, the phaB3 gene was found to be greatly downregulated when cells were grown on palm oil as the sole carbon source (Budde et al., 2010). This observation was confirmed in microarray studies comparing $R$. eutropha growth on fructose to growth on triacylglycerols (Brigham et al., 2010). In $R$. eutropha cells, the larger portion of acetoacetylCoA reductase activity is from PhaB1. Deletion of the phaB2 gene resulted in no significant decrease in reductase activity, suggesting that PhaB2 may not be a functional acetoacetyl-CoA reductase under conditions studied. Cell extracts of all $R$. eutropha strains tested revealed that NADPH was the preferred cofactor, with no change in NADHmediated reductase activity in any mutant strain (Budde et al., 2010).

\section{PhaJ, (R)-specific enoyl coenzyme-A hydratase}

Reaction: Ketoacyl-CoA $\rightarrow(\boldsymbol{R})$-3-hydroxyacylCoA

Twenty years ago, Eggink and coauthors (1992) suggested that PHA biosynthesis in Pseudomonas species utilized intermediates from fatty acid biosynthesis and degradation pathways. This hypothesis was poignant because of the observation that Pseudomonads are able 
to produce mcl-PHA regardless of carbon source used (Huisman et al., 1989; Timm, Steinbuchel, 1990; Huijberts et al., 1992). Other discoveries demonstrated that the Gram-negative soil bacterium Aeromonas caviae will only produce intracellular PHA when grown in the presence of triacylglycerols, fatty acids and similar compounds. A. caviae will not produce PHA when grown on sugars as the sole carbon source (Doi et al., 1995). The observed biosynthetic metabolism of PHA of these bacteria suggests that 3HA-CoA precursors are not constructed with acetyl-CoA as a starting material. In the case of $A$. caviae, a region in the chromosome was identified that contained all genes necessary for PHA production. Insertion of these genes in a PHB- host of $R$. eutropha conferred the ability to produce $\mathrm{P}(\mathrm{HB}-\mathrm{co}-\mathrm{HHx})$ when cells were grown on hexanoic or octanoic acids. Furthermore, it was determined that the product of one of the genes in this A. caviae gene cluster exhibited (R)specific enoyl-CoA hydratase activity. This type of enzyme activity allows cells to utilize fatty acid $\beta$-oxidation intermediates (specifically enoyl-CoA compounds) to produce monomer precursors for PHA biosynthesis (Fukui, Doi, 1997).

Since these initial, seminal discoveries regarding the mechanism of a PHA synthetic pathway alternative to that in $R$. eutropha, genes and enzymes from Pseudomonas sp., A. caviae, and other species have been studied and utilized heterologously for their ability to incorporate mcl-3HA precursors into PHA, in order to produce polymers with interesting thermal and mechanical properties. The phaJ gene from $A$. caviae (phaJAc), encoding the (R)-specific enoylCoA hydratase was expressed in E. coli and characterized. Stereospecificity of the PhaJ $A c$ enzyme was demonstrated by coupled assays involving the hydration of crotonyl-CoA. In the presence of (S)- 3HA-CoA hydratase, minimal activity from the coupled enzyme was observed.
With PhaJ activity coupled to crude extracts of $R$. eutropha in a 3HB-CoA polymerase assay, activity from the coupled enzyme system was observed, suggesting an $(R)$-stereospecificity of substrates for PhaJ (Fukui et al., 1998). In 2003, the crystal structure of PhaJAc was determined. The location of the catalytic dyad of the active site, Asp31 and His36, was determined to be deep in the substrate binding pocket. Also, residues like Leu65 and Val130 were located deep in the substrate binding pocket, suggesting preference of PhaJ for certain substrate chain lengths (Hisano et al., 2003).

Two PhaJ enzymes from $P$. aeruginosa were characterized for their substrate specificity. One, PhaJ1, showed substrate specificity for hydroxyoctanoyl-CoA, while the other, PhaJ4, demonstrated greater specificity for hydroxydecanoyl-CoA. This study also showed that both PhaJ1 and PhaJ4 from P. aeruginosa were active towards the production of shorter chain length 3HA-CoA molecules, like 3HBCoA (Davis et al., 2008). Two different PhaJ enzymes have been discovered and characterized in Pseudomonas putida, as well. One enzyme, termed PhaJ1Pp, showed substrate specificity for C8 carbon substrates, while the other, PhaJ4Pp, demonstrated high activity for both $\mathrm{C} 4$ and $\mathrm{C} 8$ substrates. Interestingly, PhaJ1Pp exhibited low (R)-stereospecificity (Sato et al., 2011).

Both phaJ from A. caviae and phaJl from $P$. aeruginosa were used to construct $R$. eutropha strains capable of producing high levels of poly(hydroxybutyrate-co-hydroxyhexanoate) (P(HB-co-HHx)) copolymer using plant oils as the sole carbon source. The $\mathrm{P}(\mathrm{HB}-c o-\mathrm{HHx})$ polymer produced contains high molar percentages of the C6 monomer, 3HHx (Budde et al., 2011). These results confirm that the PhaJ enzymes are capable of utilizing fatty acid $\beta$-oxidation intermediates as substrates in many different organisms and backgrounds. Recently, it was found that the 
genome of $R$. eutropha strain H16 contains genes encoding ( $R$ )-specific enoyl-CoA hydratase. Three gene products, PhaJ4a, PhaJ4b, and PhaJ4c, so named because they displayed primary sequence similarity to PhaJ4 in $P$. aeruginosa, were shown to have (R)-specific enoyl-CoA hydratase activity. It was determined that PhaJ4a and PhaJ4b had 10X greater catalytic efficiency than PhaJ4c. Expression of these native phaJ genes, however, results in only small amounts of HHx monomer incorporated into PHA in $R$. eutropha cells (Kawashima et al., 2011).

\section{PhaG, a 3-hydroxyacyl-ACP:CoA transferase}

Reaction: (R)-3-hydroxyacyl- $A C P \rightarrow(R)-3-$ hydroxyacyl-CoA

While production of 3HA-CoA compounds from fatty acid $\beta$-oxidation is most common and most well-studied, PHA precursors can also be produced from fatty acid biosynthesis pathways (Fig. 1). The link between fatty acid biosynthesis and PHA production was first explored in detail with the characterization of the phaG gene from P. putida and its product, a 3-hydroxyacyl-acyl carrier protein (ACP):CoA transferase. Transcription of the phaG gene was shown to occur during PHA production using gluconate as the sole carbon source. The purified enzyme was shown to transfer an acyl moiety from 3-hydroxydecanoyl-CoA to an ACP, demonstrating its transferase activity (Rehm et al., 1998). The purified $\mathrm{PhaG}$ was further characterized and several conserved amino acid residues were shown to be essential for enzyme activity. Furthermore, a conserved serine (S102) and histidine (H251) were determined to be part of the catalytic triad, along with D182 (Hoffmann et al., 2002). The phaG gene and product have also been examined in $P$. aeruginosa (Hoffmann et al., 2000), P. fluorescens (Choi et al., 2009), Pseudomonas sp. 61-3 (Matsumoto et al., 2001), and Pseudomonas mendocina (Zheng et al., 2005). The $p h a G$ gene, along with a Pseudomonas phaC PHA synthase gene, have been used in studies to demonstrate de novo production of mcl-PHA, 3-hydroxydecanoic acid and rhamnolipids in engineered E. coli (Rehm et al., 2001; Zheng et al., 2004; Wang et al., 2012).

\section{PHA Polymerase, the Agent of PHA \\ Biosynthesis \\ Reaction: $n \mathrm{HA}-\mathrm{CoA} \rightarrow \mathrm{PHA}+n \mathrm{CoA}$}

The polymerization of hydroxyalkanoate monomers is catalyzed by the PHA polymerase, typically termed $\mathrm{PhaC}$, PhaEC, or sometimes PhaRC. These polymerases are divided into four classes, depending on the subunit composition and the type of polymer synthesized. Class I synthases are the most well known and well studied, and include enzymes like $R$. eutropha PhaC. Class II synthases are those that polymerize mcl-PHA, and are typically expressed in Pseudomonas sp. Both Class I and II PHA synthases consist of one type of protein subunit, termed PhaC. Class III synthases consist of a heterodimer of the $\mathrm{PhaC}$ and $\mathrm{PhaE}$ proteins, with enzymes from Allochromatium vinosum and Thiocapsa pfennigii. The PhaC subunit is smaller in size than Class I and II PhaC proteins, with the former weighing $\sim 40 \mathrm{kDa}$ and the latter $\sim 60-70 \mathrm{kDa}$. Class IV synthases are the least well studied of the PHA polymerase enzymes, and consist of a heterodimer of $\mathrm{PhaC}$ and PhaR proteins. For Class III and Class IV synthases, the PhaE and PhaR subunits, respectively, possess hydrophobic $C$-terminal faces that likely are the contact point of the synthase and the PHA granule (Rehm, 2003). The substrate specificity of the Class III and IV synthases is scl-3HA-CoA monomers. This has been shown experimentally with a recombinantly purified $A$. vinosum $\mathrm{PhaEC}$, although the enzyme did exhibit low levels of activity using 4HB-CoA, 3HHx-CoA, and LACoA as substrates (Yuan et al., 2001). 
Table 2. Comparison of consensus active site pentapeptide sequences of PHA polymerizing and depolymerizing enzymes with lipase and esterase enzymes.

\begin{tabular}{llll}
\hline \multicolumn{1}{c}{ Enzyme } & \multicolumn{1}{c}{$\begin{array}{c}\text { Active site consensus } \\
\text { sequence }\end{array}$} & $\mathrm{n}^{\mathrm{a}}$ & \multicolumn{1}{c}{ Reference } \\
\hline $\begin{array}{l}\text { PHA synthase } \\
\begin{array}{l}\text { PHA depolymerase - } \\
\text { intracellular }\end{array}\end{array}$ & $\mathrm{GXXXG}^{\mathrm{b}}$ & 62 & (Rehm, 2003) \\
$\begin{array}{l}\text { PHA depolymerase }- \\
\text { extracellular }\end{array}$ & GXXG (GVSWG) & 21 & (Jendrossek, Handrick, 2002) \\
$\begin{array}{l}\text { Lipase } \\
\text { Esterase }\end{array}$ & 19 & $\begin{array}{l}\text { (Jendrossek, Handrick, 2002; Shinohe et } \\
\text { al., 1996) }\end{array}$ \\
\hline
\end{tabular}

${ }^{a} \mathrm{n}=$ number of sequences in the protein family aligned to derive consensus sequence

${ }^{\mathrm{b}} \mathrm{X}=$ any amino acid

${ }^{c}$ In Family IV, V, and VI esterases, the active site pentapeptide is GXSXG

Table 2 compares the active site of PHA polymerase with those of PHA depolymerases, lipase, and esterase enzymes. For the R. eutropha PHA synthase enzyme, immunocytochemical studies showed that PhaC was located on the surface of PHB granules (Gerngross et al., 1993). Following this, the active site of the enzyme was determined to be a cysteine moiety at position 319 (C319) (Gerngross et al., 1994). The catalytic triad of C319, D480, and H508 has been suggested for $R$. eutropha PhaC, based on site-directed mutagenesis studies. Also, these residues are conserved in all PHA synthases (Rehm et al., 2002). Furthermore, in vitro PHB production was demonstrated with 3HB-CoA substrate purified $R$. eutropha PhaC enzyme. The absence of any other compound in the PHB production reaction suggested that only enzyme and substrate are needed for polymer synthesis (Gerngross, Martin, 1995). Furthermore, the activity of $R$. eutropha $\mathrm{PhaC}$ was demonstrated to control the molecular weight and polydispersity of the resulting PHB (Sim et al., 1997). Data from this work suggests that PhaC from $R$. eutropha is not able to carry out PHB chain termination by itself (Lawrence et al., 2005). Thus, the manner in which the enzyme terminates elongation of a PHB chain still requires further study. Gerngross and Martin
(1995) noted that PHB synthesis by recombinant $R$. eutropha PhaC exhibited a lag in activity that could be eliminated with sufficient amounts of a detergent, Hecameg. The lag phase was later confirmed, but it was determined that addition of Hecameg merely shortened but did not eliminate the lag in activity (Yuan et al., 2001). Studies involving acylation of $R$. eutropha $\mathrm{PhaC}$ using a saturated trimer (sT-CoA) analog of $[3 \mathrm{HB}]_{3}-\mathrm{CoA}$ demonstrated that the lag phase in activity was significantly reduced and activity was increased. It was suggested that the addition of sT-CoA to the reaction mixture facilitated dimerization when the sT moiety bound to the active site of the enzyme (Jia et al., 2001). Recently, activity of epitope-tagged PhaC, purified from the native $R$. eutropha, exhibited no lag phase. This result was due to the presence of different fractions of PHA synthase, monomer and dimer fractions that still exhibited lag in activity, and a high molecular weight (HMW) fraction that did not lag. It was shown that the HMW fraction consisted of copurifying components like oligomeric PHB and the PhaP1 phasin protein. Thus, these "minigranules," with PHB or oligo-3HB bound to the active site included primed, dimerized synthase enzymes, thus exhibiting no lag in enzyme activity (Cho et al., 2012). In addition, 
a recent examination of a Class I PHA synthase from Chromobacterium sp. demonstrated an enzyme activity 5-fold greater than that of the $R$. eutropha PhaC enzyme (Bhubalan et al., 2011). This discovery, coupled with the experimentally determined broad substrate specificity of the Chromobacterium sp. PhaC enzyme (Bhubalan et al., 2011; Ling et al., 2011), has biotechnological implications in improvement of the PHA production process.

In their $R$. eutropha PhaC localization studies, Gerngross and coworkers (1993) proposed a model of granule biogenesis where PHA synthases containing nascent PHB chains would aggregate together at random nucleation sites to form intracellular polymer granules. This micelle model of PHB granule formation (Fig.3A) was one of three original models proposed in the literature. A scaffold model was also proposed (Fig.3C), with similarities to the micelle model, except including intracellular sites of nucleation called "mediation elements," which were darkstained structures that appeared in electron microscopy studies of PHB granule formation in R. eutropha (Tian et al., 2005a; Tian et al., 2005b). The membrane budding model (Fig.3B), where hydrophobic PHA interacts with the hydrophobic lipids of the cell membrane and polymer granules nucleate at the site of the membrane, was suggested both because it is analogous to lipid body formation in eukaryotic systems (Parthibane et al., 2012; Stubbe et al., 2005) and as a result of fluorescence microscopy studies (Cho et al., 2012; Jendrossek, 2005; Jendrossek, 2009). The caveat of the membrane budding model is that many of the studies that led to its proposition were performed in an artificial system, using fluorescent tagged granule associated proteins for localization (Jendrossek, 2005; Jendrossek, 2009) or using E. coli as the host organism (Peters et al., 2007). Recently, a modified micelle model has been proposed (Fig.3D), which involves not only the PhaC enzyme in R. eutropha, but also the PhaP1 phasin protein. The principles of the micelle model and the modified micelle model are similar, with the exception that in the modified micelle model, nascent PHB chains are complexed with $\mathrm{PhaP} 1$ proteins in order to maintain solubility of the nascent granule. It has been demonstrated that another newly-discovered granule associated protein, PhaM, has both PHB binding and DNA binding capabilities (Fig.1). The PhaM protein may bind nonspecifically to the $R$. eutropha nucleoid to provide sites of PHA granule nucleation (Pfeiffer et al., 2011). It has thus been suggested that the "mediation elements" as seen in earlier electron microscopy studies are the nucleoid region of $R$. eutropha.

Class II PHA synthases, like those found in P. putida, P. aeruginosa, and others, preferentially utilize mcl-3HA-CoA as substrates for polymer biosynthesis. They typically consist of one type of protein subunit, $\mathrm{PhaC}$, which is $60-65 \mathrm{kDA}$ in size (Rehm, 2003). The region of DNA containing the PHA synthase genes from $P$. aeruginosa strain PA01 was first cloned and characterized in 1992. At that time, it was hypothesized that the cysteine moiety at position 296 (C296, analogous to C319 from $R$. eutropha $\mathrm{PhaC}$ ) was responsible for the transesterification reaction (Timm, Steinbuchel, 1992). A catalytic triad of C296, D452, and H453, has been suggested by construction of threading models and by site-directed mutagenesis (Amara, Rehm, 2003). It was shown that expression of $P$. aeruginosa phaCl, heterologoulsly expressed in E. coli, conferred mcl-PHA biosynthesis capabilities. The E. coli strain used in this study was a $f a d B$ mutant strain, which resulted in the accumulation of mcl-3HA-CoA precursors for polymer synthesis (Langenbach et al., 1997). Similarly, expression of $P$. aeruginosa phaC2 was shown to confer mcl-PHA synthesis capabilities in the same strain of $E$. coli (Qi et al., 1997). It has been shown in Pseudomonas stutzieri that PhaC1 


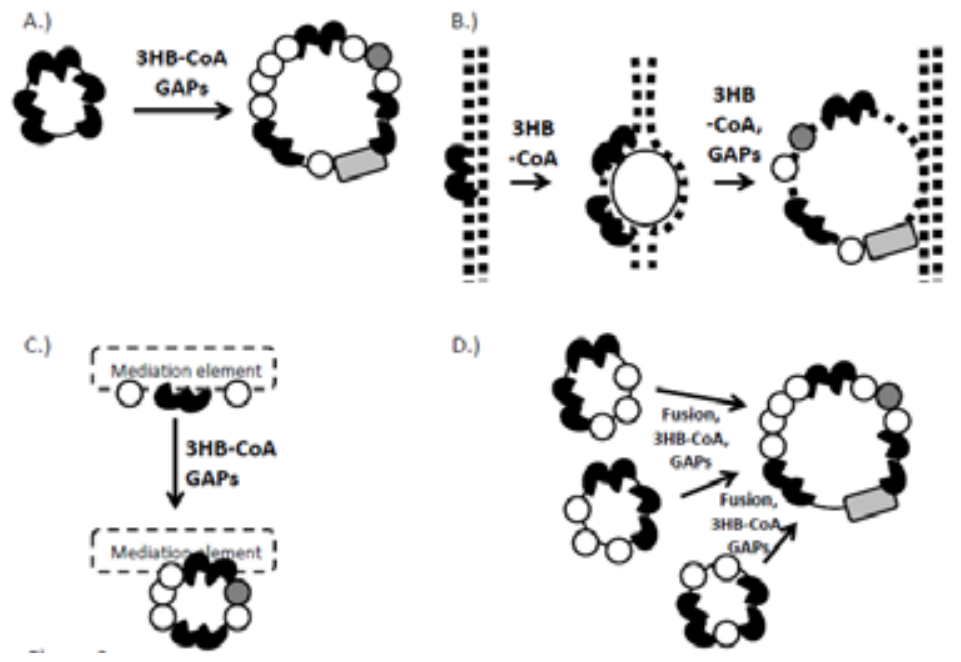

Fig. 3. Ralstonia eutropha granule biogenesis models. (A) The micelle model; (B) the membrane budding model; (C) the scaffold model; and (D) the modified micelle model. Symbols represent the same enzymes as in Fig. 1

and $\mathrm{PhaC} 2$ exhibit different substrate specificities, with $\mathrm{PhaC} 1$ specific to mcl-3HA-CoA substrates and $\mathrm{PhaC} 2$ able to utilize both scl- and mcl-3HACoA substrates (Chen et al., 2004; Chen et al., 2006). The enzymatic activities of recombinantly expressed and purified $P$. aeruginosa $\mathrm{PhaC} 1$ and PhaC2 were measured using 3-hydroxydecanoyl$\mathrm{CoA}$ as the substrate. Activities of $\mathrm{PhaCl}$ and PhaC2 were reported to be 0.039 activity units per $\mathrm{mg}(\mathrm{U} / \mathrm{mg})$ and $0.035 \mathrm{U} / \mathrm{mg}$, respectively. Free coenzyme-A was shown to inhibit the polymerization reaction with a $\mathrm{K}_{\mathrm{i}}$ of $85 \mu \mathrm{M}$ (Qi et al., 2000). Interestingly, a PHA synthase from Pseudomonas sp. 61-3 has been characterized, and it has been found to exhibit broad substrate specificity (3HA monomers of 4-12 carbon atoms in length) (Matsusaki et al., 1998). Expression of Pseudomonas sp. 61-3 phaC in R. eutropha was shown to confer the ability to synthesize poly(hydroxybutyrate-co-hydroxyalkanoate) (P(HB-co-HA)) copolymers, where HA consisted of monomers of 6-12 carbon atoms in chain length (Matsusaki et al., 2000). Engineering of Pseudomonas sp. 61-3 PhaC by mutagenesis of serine residue at position 477 and a glutamine residue at position 481 resulted in increased $3 \mathrm{HB}$ fractions in the resulting polymer (Shozui et al., 2009), suggesting these residues play a role in substrate specificity. This synthase was also engineered to accept LA-CoA as a substrate in the seminal engineering studies of a $\mathrm{P}(\mathrm{LA}-\mathrm{co}-\mathrm{HB})$ producing bacterium (Taguchi et al., 2008).

As stated previously, A. caviae is able to produce $\mathrm{P}(\mathrm{HB}-\mathrm{co}-\mathrm{HHx})$ copolymer when grown on oils or fatty acids. This suggests that the PHA synthase of $A$. caviae has broad substrate specificity and can accommodate both scl- and mcl-3HA monomers. The initial isolation and characterization of the A. caviae PhaC showed that the active site was similar to the R. eutropha enzyme (Fukui, Doi, 1997). Higher enzyme activity mutants of $A$. caviae phaC have been isolated (Taguchi et al., 2001; Kichise et al., 2002). Both of these mutants displayed a concomitant increase in 3HHx monomer incorporation along with increase in activity. The mutations in the higher activity synthases were found to be in two codons that were not highly conserved among PHA synthases, N149S and D171G (Kichise et al., 2002). The genes encoding the higher activity 
synthases were expressed in the R. eutropha mutant strain PHB-4. The PHA produced from these strains in cultures with soybean oil as the sole carbon source consisted of a maximum of $5 \mathrm{~mol} \%$ 3HHx monomer (Tsuge et al., 2004). The two mutations, N149S and D171G, were combined on one phaC gene and examined for their synergistic effects. An R. eutropha strain expressing the double mutant synthase produced PHA with $5.2 \mathrm{~mol} \% 3 \mathrm{HHx}$ and $18.1 \mathrm{~mol} \% 3 \mathrm{HHx}$ when cultivated on soybean oil and octanoic acid, respectively. In both cases the double mutant exhibited an increase in $3 \mathrm{HHx}$ content compared to the wild type and single mutant synthases, suggesting a synergistic effect of the two mutations in terms of $3 \mathrm{HHx}$ incorporation into PHA (Tsuge et al., 2007). Chimeric PHA synthases were engineered using the sequences from R. eutropha phaC and A. caviae phaC. When expressed in E. coli, a recombinant synthase consisting of the $N$-terminal 25\% (amino acids 1-154) of the A. caviae $\mathrm{PhaC}$ and the $C$-terminal $75 \%$ (amino acids 155-589) of the R. eutropha $\mathrm{PhaC}$, the maximum amount of intracellular PHA was recovered, compared to strains expressing the other chimeric mutants and the wild type synthases. Also, 2 mol\% $3 \mathrm{HHx}$ was incorporated into PHA, suggesting that the $N$-terminal region of $A$. caviae PhaC conferred broader substrate specificity (Matsumoto et al., 2009). This makes sense as the N149 residue, which has been shown to affect substrate specificity, is present on this $N$-terminal portion of the chimera.

\section{PhaZ, PHA depolymerases, and PHA Breakdown}

Reaction: $\mathrm{PHA}+n \mathrm{CoA} \rightarrow n \mathrm{HA}-\mathrm{CoA}$, or PHA $+n \mathrm{H} 2 \mathrm{O} \rightarrow \mathrm{HA}$

Saegusa and coworkers (2001) were the first to characterize an intracellular PHA depolymerase in R. eutropha. Soon after this initialcharacterizationofadepolymeraseenzyme,
York et al. (2003) determined that $R$. eutropha expressed multiple PHA depolymerases. Two of them, PhaZ1 and PhaZ2, played significant roles in PHB mobilization. In a recent study, intracellular PHB depolymerases were shown to have an effect on granule architecture, with PhaZ2 implicated to be involved with granule density (Brigham et al., 2012). Intracellular PHA depolymerases have been shown to be specific to native PHA (nPHA), which is found in intact intracellular granules. Typically, intracellular PHA depolymerases do not act on crystalline PHA, or polymer not present in intracellular granules (Gebauer, Jendrossek, 2006). PhaZ1 from $R$. eutropha was determined to mobilize PHB by thiolysis, using CoA as a co-substrate, resulting in the formation of $3 \mathrm{HB}-\mathrm{CoA}$ from purified PHB granules. This thiolysis reaction still occurred, albeit to a lesser extent, when granules lacking PhaZ1 were used (Uchino et al., 2007). This thiolysis in the absence of PhaZ1 could indicate that other PhaZ enzymes present on the PHB granule also mobilize PHB in the presence of CoA. Furthermore, hydrolysis of PHB to 3HB has been demonstrated using E. coli recombinantly expressing the PHB biosynthesis operon phaCAB and phaZ1 genes (Uchino et al., 2008). It is unclear at this time whether hydrolysis and thiolysis of PHB suggests conflicting evidence as to the true mechanism of PhaZ activity. It is clear that more evidence is needed, preferably resulting from standardized assays that mimic in vivo conditions as closely as possible, to determine the true mechanism of PhaZ-mediated intracellular PHB mobilization.

Enzymology of extracellular PHA depolymerases is more well-studied, likely because model systems have proven to be more readily characterizable. Recombinantly expressed and purified PHB depolymerase from Alcaligenes faecalis (now known as Ralstonia pickettii) was shown to cleave oligomers of $3 \mathrm{HB}$ 
containing 3 or more subunits. It was suggested that the enzyme had 4 hydroxybutyryl binding sites, 3 of which must be occupied for cleavage to take place. Further characterization showed that two of the binding sites, flanking the site of PHB cleavage, exhibited (R)-specific stereoselectivity (Bachmann, Seebach, 1999). A highly active, thermotolerant depolymerase, PhaZ7, from Paucimonas lemoignei has been characterized biochemically, and is a serine hydrolase containing the pentapeptide motif AHSMG at the active site where the serine residue is at position 136 (S136). Alteration of this pentapeptide motif to a lipase box consensus or a PHB depolymerase box consensus had no significant effect of the activity of PhaZ7 (Braaz et al., 2003). Also, the catalytic triad of PhaZ7 has been demonstrated to be residues S136, D242, and H306 (Handrick et al., 2001). This catalytic triad suggests a mechanism of action similar to lipases and serine esterases, where S136 attacks the carbonyl carbon of a bound PHB chain (Handrick et al., 2001; Papageorgiou et al., 2008). As mentioned above, the substrate binding domain of another PHA depolymerase, $\mathrm{PhaZ}_{\text {RpiT1 }}$ from $R$. pickettii strain $\mathrm{T} 1$ has been described. Random mutagenesis and high throughput screening identified residues like V415, L441, and V457 that play a role in hydrophobic interactions during substrate binding (Hiraishi et al., 2006). In addition, directed mutagenesis showed that residues L441, Y443, and S445 play crucial roles in substrate binding in $\mathrm{PhaZ}_{\mathrm{RpiT1}}$ (Hiraishi et al., 2010). The crystal structure of $P$. lemoignei PhaZ7 has been determined to a $1.9 \AA$ resolution. However, even with this resolution, a substrate binding pocket was not able to be identified, suggesting considerable structural rearrangement during catalysis (Papageorgiou et al., 2008). Recently, a crystal structure of PhaZ7 with a $1.2 \AA$ resolution has been solved, revealing substrate binding information. With the updated structure, the active site is still found to be deeply buried, but conformational changes of surface loops were identified, suggesting involvement in PHA binding (Wakadkar et al., 2010).

The ability to degrade PHA in an extracellular environment is widely distributed among microorganisms. Bacteria and fungi have been characterized to degrade PHA (Jendrossek, Handrick, 2002). In an early study, lipases and PHA depolymerases from both prokaryotic and eukaryotic sources were examined for their ability to degrade PHA homopolymers. Lipases were unable to degrade PHB, but did show polymer degradation activity against polyhydroxypropionate (PHP) and poly(4hydroxybutyrate) (P4HB). PHB depolymerases, on the other hand, were able to readily degrade PHB and demonstrated more robust activity against PHB and P4HB (Mukai et al., 1993). These results suggested that, while lipases exhibit PHA degradation capabilities, the polymers are degraded more rapidly with the aid of de facto PHB depolymerase enzymes. Early environmental studies of biodegradation of PHA polymers showed that $\mathrm{PHB}$, and $\mathrm{P}(\mathrm{HB}-\mathrm{co}-\mathrm{HV})$ were degraded significantly in soil and aqueous environments. The rate of copolymer degradation was faster than that of PHB degradation. The PHA degrading organisms in the soil microbial communities consisted of a variety of bacteria and fungi. Common fungal genera among the fungi were Aspergillus and Penicillium (Mergaert, Swings, 1996). PHA degrading species in microbial communities have also been examined in root microbial ecosystems of coniferous and deciduous trees (Boyandin et al., 2012). While there is a wealth of ecological information in the literature regarding PHA degradation in environmental isolates and communities, very little biochemical characterization has been performed. 
Table 3. Unanswered questions in the field of PHA homeostasis research.

Enzyme activity and role in PHA homeostasis - Questions and subjects for further research

\author{
- Crystal structure of PHA synthase enzyme \\ - Cellular regulation of PHA production and PHA-related gene expression \\ - Characterization of PHA as a stress response molecule \\ - Correlation of PhaZ expression v. function in R. eutropha \\ - Defined roles of each intracellular PHB depolymerase in $R$. eutropha \\ - Characterization of intracellular PHB depolymerase reactions in vivo
}

\section{Conclusions}

Since the discovery and characterization of the original PHA biosynthesis pathways, many advances have been made in biochemical characterizations of the enzymes involved. There are, however, many unanswered questions in PHA pathway biochemistry, including those listed in Table 3. While crystal structures have been solved for some enzymes involved in PHA biosynthesis, the "holy grail" crystal structure of PhaC has yet to be successfully undertaken (Table 3). Also, understanding of PHA depolymerization in the intracellular and extracellular environments will shed light on PHA homeostasis on cellular and environmental levels. Further refinement of the enzymology of the PHA biosynthesis pathways can lead to production of polymers with tailormade properties, made possible by directed evolution of enzyme active sites and substrate binding domains. These active sites and domains must be established and well understood in many of the enzymes discussed in this review before the production of tailor-made PHA becomes a reality.

\section{Acknowledgements}

The study was supported by the project initiated by the Government of the Russian Federation (Decree No. 220 of 09.04.2010) for governmental support of scientific research conducted under the guidance of leading scientists at Russian Institutions of Higher Education (Agreement No. 11.G34.31.0013).

We thank Ms. Jingnan Lu and Mr. John W. Quimby for critical review of the manuscript prior to submission. We also thank our colleagues from the Shishatskaya and Volova groups at Siberian Federal University for their help and support, including especially the opportunity to publish this review. C.J.B. is funded by Advanced Research Projects - energy (ARPA-E).

\title{
References
}

Amara A.A., Rehm B.H. (2003) Replacement of the catalytic nucleophile cysteine-296 by serine in class II polyhydroxyalkanoate synthase from Pseudomonas aeruginosa-mediated synthesis of a new polyester: identification of catalytic residues. Biochem. J. 374: 413-421.

Anderson A.J., Dawes E.A. (1990) Occurrence, metabolism, metabolic role, and industrial uses of bacterial polyhydroxyalkanoates. Microbiol. Rev. 54: 450-472.

Anderson A.J., Haywood G.W., Dawes E.A. (1990) Biosynthesis and composition of bacterial poly(hydroxyalkanoates). Int. J. Biol. Macromol. 12: 102-105.

Andreessen B., Lange A.B., Robenek H., Steinbüchel A. (2010) Conversion of glycerol to poly(3hydroxypropionate) in recombinant Escherichia coli. Appl. Environ. Microbiol. 76: 622-626. 
Andreessen B., Steinbuchel A. (2010) Biosynthesis and biodegradation of 3-hydroxypropionatecontaining polyesters. Appl. Environ. Microbiol. 76: 4919-4925.

Arpigny J.L., Jaeger K.E. (1999) Bacterial lipolytic enzymes: classification and properties. Biochem. J. 343 Pt 1: 177-183.

Bachmann B.M., Seebach D. (1999) Investigation of the enzymatic cleavage of diastereomeric oligo(3-hydroxybutanoates) containing two to eight HB units. A model for the stereoselectivity of PHB depolymerase from Alcaligenes faecalis $\mathrm{T}_{1}$. Macromolecules. 32: 1777-1784.

Bhubalan K., Chuah J.A., Shozui F., Brigham C.J., Taguchi S., Sinskey A.J., Rha C., Sudesh K. (2011) Characterization of the Highly Active Polyhydroxyalkanoate Synthase of Chromobacterium sp. Strain USM2. Appl. Environ. Microbiol. 77: 926-2933.

Bloomfield G., Sandhu G., Carr N.G. (1969) Activation by Hg(2+) of acetoacetyl-CoA reductase in extracts of Rhodopseudomonas spheroides and Rhodomicrobium vannielii. FEBS Lett. 5: 246-248.

Boyandin A.N., Prudnikova S.V., Filipenko M.L., Khrapov E.A., Vasil'ev A.D., Volova T.G. (2012) Biodegradation of polyhydroxyalkanoates by soil microbial communities of different structures and detection of PHA degrading microorganisms. Appl. Biochem. Microbiol. 48: 35-44.

Braaz R., Handrick R., Jendrossek D. (2003) Identification and characterisation of the catalytic triad of the alkaliphilic thermotolerant PHA depolymerase PhaZ7 of Paucimonas lemoignei. FEMS Microbiol. Lett. 224: 107-112.

Brigham C.J., Budde C.F., Holder J.W., Zeng Q., Mahan A.E., Rha C., Sinskey A.J. (2010) Elucidation of beta-oxidation pathways in Ralstonia eutropha H16 by examination of global gene expression. J. Bacteriol. 192: 5454-5464.

Brigham C.J., Kurosawa K., Rha C.K., Sinskey A.J. (2011) Bacterial carbon storage to value added products. J. Microbial Biochem. Technol. 83: S3 - 002.

Brigham C.J., Reimer E.N., Rha C., Sinskey A.J. (2012) Examination of PHB Depolymerases in Ralstonia eutropha: Further Elucidation of the Roles of Enzymes in PHB Homeostasis. AMB Express 2: 26 .

Budde C.F., Mahan A.E., Lu J., Rha C., Sinskey A.J. (2010) Roles of multiple acetoacetyl coenzyme A reductases in polyhydroxybutyrate biosynthesis in Ralstonia eutropha H16. J. Bacteriol. 192: 5319-5328.

Budde C.F., Riedel S.L., Willis L.B., Rha C., Sinskey A.J. (2011) Production of poly(3hydroxybutyrate-co-3-hydroxyhexanoate) from plant oil by engineered Ralstonia eutropha strains. Appl. Environ. Microbiol. 77: 2847-2854.

Chen G.Q. (2009) A microbial polyhydroxyalkanoates (PHA) based bio- and materials industry. Chem Soc Rev. 38: 2434-2446.

Chen J.Y., Liu T., Zheng Z., Chen J.C., Chen G.Q. (2004) Polyhydroxyalkanoate synthases PhaC1 and $\mathrm{PhaC} 2$ from Pseudomonas stutzeri 1317 had different substrate specificities. FEMS Microbiol. Lett. 234: 231-237.

Chen J.Y., Song G., Chen G.Q. (2006) A lower specificity PhaC2 synthase from Pseudomonas stutzeri catalyses the production of copolyesters consisting of short-chain-length and medium-chainlength 3-hydroxyalkanoates. Antonie Van Leeuwenhoek. 89: 157-167.

Cho M., Brigham C.J., Sinskey A.J., Stubbe J. (2012) Purification of polyhydroxybutyrate synthase from its native organism, Ralstonia eutropha: implications for the initiation and elongation of polymer formation in vivo. Biochemistry. 51: 2276-2288. 
Choi M.H., Xu J., Rho J.K., Shim J.H., Yoon S.C. (2009) Shifting of the distribution of aromatic monomer-units in polyhydroxyalkanoic acid to longer units by salicylic acid in Pseudomonas fluorescens BM07 grown with mixtures of fructose and 11-phenoxyundecanoic acid. Biotechnol. Bioeng. 102: 1209-1221.

Chung A., Liu Q., Ouyang S.-P., Wu Q., Chen G.-Q. (2009) Microbial production of 3-hydroxydodecanoic acid by pha operon and fadBA knockout mutant of Pseudomonas putida KT2442 harboring tesB gene. Appl. Microbiol. Biotechnol. 83: 513-519.

Cramm R. (2009) Genomic view of energy metabolism in Ralstonia eutropha H16. J. Mol. Microbiol. Biotechnol. 16: 38-52.

Davis J.T., Chen H.H., Moore R., Nishitani Y., Masamune S., Sinskey A.J., Walsh C.T. (1987a) Biosynthetic thiolase from Zoogloea ramigera. II. Inactivation with haloacetyl CoA analogs. J. Biol. Chem. 262: 90-96.

Davis J.T., Moore R.N., Imperiali B. \& others (1987b) Biosynthetic thiolase from Zoogloea ramigera. I. Preliminary characterization and analysis of proton transfer reaction. J. Biol. Chem. 262: 82-89.

Davis R., Chandrashekar A., Shamala T. R. (2008) Role of (R)-specific enoyl coenzyme A hydratases of Pseudomonas sp in the production of polyhydroxyalkanoates. Antonie Van Leeuwenhoek. 93: 285-296.

Doi Y., Kitamura S., Abe H. (1995) Microbial Synthesis and Characterization of Poly(3hydroxybutyrate-co-3-hydroxyhexanoate). Macromolecules. 28: 4822-4828.

Eggink G., deWaard P., Huijberts G.N.M. (1992) The role of fatty acid biosynthesis and degradation in the supply of substrates for poly(3-hydroxyalkanoate) formation in Pseudomonas putida. FEMS Microbiol. Lett. 103: 159-163.

Fukui T., Doi Y.(1997)Cloning and analysis of the poly(3-hydroxybutyrate-co-3-hydroxyhexanoate) biosynthesis genes of Aeromonas caviae. J. Bacteriol. 179: 4821-4830.

Fukui T., Shiomi N., Doi Y. (1998) Expression and characterization of(R)-specific enoyl coenzyme A hydratase involved in polyhydroxyalkanoate biosynthesis by Aeromonas caviae. J. Bacteriol. 180: 667-673.

Gebauer B., Jendrossek D. (2006) Assay of poly(3-hydroxybutyrate) depolymerase activity and product determination. Appl. Environ. Microbiol. 72: 6094-6100.

Gerngross T.U., Reilly P., Stubbe J., Sinskey A.J., Peoples O.P. (1993) Immunocytochemical analysis of poly-beta-hydroxybutyrate (PHB) synthase in Alcaligenes eutrophus H16: localization of the synthase enzyme at the surface of PHB granules. J. Bacteriol. 175: 5289-5293.

Gerngross T.U., Snell K.D., Peoples O.P., Sinskey A.J., Csuhai E., Masamune S., Stubbe J. (1994) Overexpression and purification of the soluble polyhydroxyalkanoate synthase from Alcaligenes eutrophus: evidence for a required posttranslational modification for catalytic activity. Biochemistry. 33: 9311-9320.

Gerngross T.U., Martin D.P.(1995) Enzyme-catalyzed synthesis of poly[(R)-(-)-3-hydroxybutyrate]: formation of macroscopic granules in vitro. Proc. Natl. Acad. Sci. USA. 92: 6279-6283.

Gupta R., Gupta N., Rathi P. (2004) Bacterial lipases: an overview of production, purification and biochemical properties. Appl. Microbiol. Biotechnol. 64: 763-781.

Han J., Lu Q., Zhou L., Liu H., Xiang H. (2009) Identification of the polyhydroxyalkanoate (PHA)specific acetoacetyl coenzyme A reductase among multiple FabG paralogs in Haloarcula hispanica 
and reconstruction of the PHA biosynthetic pathway in Haloferax volcanii. Appl. Environ. Microbiol. 75: 6168-6175.

Handrick R., Reinhardt S., Focarete M.L., Scandola M., Adamus G., Kowalczuk M., Jendrossek D. (2001) A new type of thermoalkalophilic hydrolase of Paucimonas lemoignei with high specificity for amorphous polyesters of short chain-length hydroxyalkanoic acids. J.Biol. Chem. 276: 3621536224.

Hiraishi T., Hirahara Y., Doi Y., Maeda M., Taguchi S. (2006) Effects of mutations in the substratebinding domain of poly[(R)-3-hydroxybutyrate] (PHB) depolymerase from Ralstonia pickettii $\mathrm{T} 1$ on PHB degradation. Appl. Environ. Microbiol. 72: 7331-7338.

Hiraishi T., Komiya N., Maeda M. (2010) Y443F mutation in the substrate-binding domain of extracellular PHB depolymerase enhances its PHB adsorption and disruption abilities. Polym. Degrad. Stabil. 95: 1370-1374.

Hiramatsu M., Doi Y. (1993) Microbial synthesis and characterization of poly(3-hydroxybutyrateco-3-hydroxypropionate). Polymer. 34: 4782-4786.

Hisano T., Tsuge T., Fukui T., Iwata T., Miki K., Doi Y. (2003) Crystal structure of the (R)-specific enoyl-CoA hydratase from Aeromonas caviae involved in polyhydroxyalkanoate biosynthesis. J. Biol. Chem. 278: 617-624.

Hoffmann N., Steinbuchel A., Rehm B.H. (2000) The Pseudomonas aeruginosa phaG gene product is involved in the synthesis of polyhydroxyalkanoic acid consisting of medium-chain-length constituents from non-related carbon sources. FEMS Microbiol. Lett. 184: 253-259.

Hoffmann N., Amara A.A., Beermann B.B., Qi Q., Hinz H.J., Rehm B.H. (2002) Biochemical characterization of the Pseudomonas putida 3-hydroxyacyl ACP:CoA transacylase, which diverts intermediates of fatty acid de novo biosynthesis. J. Biol. Chem. 277: 42926-42936.

Huijberts G.N., Eggink G., de Waard P., Huisman G.W., Witholt B. (1992). Pseudomonas putida KT2442 cultivated on glucose accumulates poly(3-hydroxyalkanoates) consisting of saturated and unsaturated monomers. Appl. Environ. Microbiol. 58: 536-544.

Huisman G.W., de Leeuw O., Eggink G., Witholt B. (1989) Synthesis of poly-3-hydroxyalkanoates is a common feature of fluorescent pseudomonads. Appl. Environ. Microbiol. 55: 1949-1954.

Ishizaki A., Tanaka K., Taga N. (2001) Microbial production of poly-D-3-hydroxybutyrate from $\mathrm{CO}_{2}$. Appl. Microbiol. Biotechnol. 57: 6-12.

Jaeger K.E., Dijkstra B.W., Reetz M.T. (1999) Bacterial biocatalysts: molecular biology, threedimensional structures, and biotechnological applications of lipases. Annu. Rev. Microbiol. 53: 315351 .

Jendrossek D., Handrick R. (2002). Microbial degradation of polyhydroxyalkanoates. Annu. Rev. Microbiol. 56: 403-432.

Jendrossek D. (2005) Fluorescence microscopical investigation of poly(3-hydroxybutyrate) granule formation in bacteria. Biomacromolecules 6: 598-603.

Jendrossek D. (2009) Polyhydroxyalkanoate granules are complex subcellular organelles (carbonosomes). J. Bacteriol. 191: 3195-3202.

Jia Y., Yuan W., Wodzinska J., Park C., Sinskey A.J., Stubbe J. (2001). Mechanistic studies on class I polyhydroxybutyrate (PHB) synthase from Ralstonia eutropha: class I and III synthases share a similar catalytic mechanism. Biochemistry 40: 1011-1019. 
Kawashima Y., Cheng W., Mifune J., Orita I., Nakamura S., Fukui T. (2011) Characterization and functional analyses of R-specific enoyl coenzyme A hydratases in polyhydroxyalkanoate-producing Ralstonia eutropha. Appl. Environ. Microbiol. 78: 493-502.

Kichise T., Taguchi S., Doi Y. (2002) Enhanced accumulation and changed monomer composition in polyhydroxyalkanoate (PHA) copolyester by in vitro evolution of Aeromonas caviae PHA synthase. Appl. Environ. Microbiol. 68: 2411-2419.

Lageveen R.G., Huisman G.W., Preusting H., Ketelaar P., Eggink G., Witholt B. (1988). Formation of polyesters by Pseudomonas oleovorans: Effect of substrates on formation and composition of poly-(R)-3hydroxyalkanoates and poly-(R)-3-hydroxyalkenoates. Appl. Environ. Microbiol. 54: 2924-2932.

Langenbach S., Rehm B.H., Steinbuchel A. (1997) Functional expression of the PHA synthase gene phaCl from Pseudomonas aeruginosa in Escherichia coli results in poly(3-hydroxyalkanoate) synthesis. FEMS Microbiol. Lett. 150: 303-309.

Lawrence A.G., Choi J., Rha C., Stubbe J., Sinskey A.J. (2005) In vitro analysis of the chain termination reaction in the synthesis of poly-(R)-beta-hydroxybutyrate by the class III synthase from Allochromatium vinosum. Biomacromolecules. 6: 2113-2119.

Lee S.H., Oh D.H., Ahn W.S., Lee Y., Choi J., Lee S.Y. (2000) Production of poly(3-hydroxybutyrate-co-3hydroxyhexanoate) by high-cell-density cultivation of Aeromonas hydrophila. Biotechnol. Bioeng. 67: 240-244.

Lemoigne M. (1927) Études sur l'autolyse microbienne origine de l'acide b-oxybutyrique formé par autolyse. Ann. Inst. Pasteur. 41: 148-165.

Li S.Y., Dong C.L., Wang S.Y., Ye H.M., Chen G.Q. (2011) Microbial production of polyhydroxyalkanoate block copolymer by recombinant Pseudomonas putida. Appl. Microbiol. Biotechnol. 90: 659-669.

Lindenkamp N., Peplinski K., Volodina E., Ehrenreich A., Steinbuchel A. (2010) Impact of multiple beta-ketothiolase deletion mutations in Ralstonia eutropha H16 on the composition of 3-mercaptopropionic acid-containing copolymers. Appl. Environ. Microbiol. 76: 5373-5382.

Ling S.C., Tsuge T., Sudesh K. (2011) Biosynthesis of novel polyhydroxyalkanoate containing 3-hydroxy-4-methylvalerate by Chromobacterium sp. USM2. J. Appl. Microbiol. 111: 559-571.

Masamune S., Palmer M.A.J., Gamboni R., Thompson S., Davis J.T., Peoples O.P., Sinskey A.J., Walsh C.T. (1989a) Bio-Claisen condensation catalyzed by thiolase from Zoogloea ramigera. Active site cysteine residues. J. Am. Chem. Soc. 111: 1879-1881.

Masamune S., Walsh C.T., Sinskey A.J., Peoples O.P. (1989b) Poly-(R)-3-hydroxybutyrate (PHB) biosynthesis: mechanistic studies on the biological Claisen condensation catalyzed by $\beta$-ketoacyl thiolase. Pure Appl. Chem. 61: 303-312.

Matsumoto K., Matsusaki H., Taguchi S., Seki M., Doi Y. (2001) Cloning and characterization of the Pseudomonas sp. 61-3 phaG gene involved in polyhydroxyalkanoate biosynthesis. Biomacromolecules. 2: $142-147$.

Matsumoto K., Takase K., Yamamoto Y., Doi Y., Taguchi S. (2009) Chimeric enzyme composed of polyhydroxyalkanoate (PHA) synthases from Ralstonia eutropha and Aeromonas caviae enhances production of PHAs in recombinant Escherichia coli. Biomacromolecules. 10: 682-685.

Matsumoto K., Taguchi S. (2010) Enzymatic and whole-cell synthesis of lactate-containing polyesters: toward the complete biological production of polylactate. Appl. Microbiol. Biotechnol. 85: 921-932. 
Matsusaki H., Manji S., Taguchi K., Kato M., Fukui T., Doi Y. (1998) Cloning and molecular analysis of the poly(3-hydroxybutyrate) and poly(3-hydroxybutyrate-co-3-hydroxyalkanoate) biosynthesis genes in Pseudomonas sp. strain 61-3. J. Bacteriol. 180: 6459-6467.

Matsusaki H., Abe H., Taguchi K., Fukui T., Doi Y. (2000) Biosynthesis of poly(3-hydroxybutyrateco-3-hydroxyalkanoates) by recombinant bacteria expressing the PHA synthase gene phaCl from Pseudomonas sp. 61-3. Appl. Microbiol. Biotechnol. 53: 401-409.

Mauchline W.S., Araujo R., Wait R., Dowsett A.B., Dennis P.J., Keevil C.W. (1992) Physiology and morphology of Legionella pneumophila in continuous culture at low oxygen concentration. J. Gen. Microbiol. 138: 2371-2380.

Mergaert J., Swings J. (1996) Biodiversity of microorganisms that degrade bacterial and synthetic polymers. J. Ind. Microbiol. 17: 463-469.

Merrick J.M., Lundgren D.G., Pfister R.M. (1965) Morphological Changes in Poly-BetaHydroxybutyrate Granules Associated with Decreased Susceptibility to Enzymatic Hydrolysis. J. Bacteriol. 89: 234-239.

Mukai K., Doi Y., Sema Y., Tomita K. (1993) Substrate specificities in hydrolysis of polyhydroxyalkanoates by microbial esterases. Biotechnol. Lett. 15: 601-604.

Palmer M.A., Differding E., Gamboni R., Williams S.F., Peoples O.P., Walsh C.T., Sinskey A.J., Masamune S. (1991) Biosynthetic thiolase from Zoogloea ramigera. Evidence for a mechanism involving Cys-378 as the active site base. J. Biol. Chem. 266: 8369-8375.

Papageorgiou A.C., Hermawan S., Singh C.B., Jendrossek D. (2008) Structural basis of poly(3hydroxybutyrate) hydrolysis by PhaZ7 depolymerase from Paucimonas lemoignei. J. Mol. Biol. 382: 1184-1194.

Parthibane V., Rajakumari S., Venkateshwari V., Iyappan R., Rajasekharan R. (2012) Oleosin is bifunctional enzyme that has both monoacylglycerol acyltransferase and phospholipase activities. J. Biol. Chem. 287: 1946-1954.

Peoples O.P., Masamune S., Walsh C.T., Sinskey A.J. (1987) Biosynthetic thiolase from Zoogloea ramigera. III. Isolation and characterization of the structural gene. J. Biol. Chem. 262: 97-102.

Peoples O. P., Sinskey A.J. (1989a) Poly-beta-hydroxybutyrate (PHB) biosynthesis in Alcaligenes eutrophus H16. Identification and characterization of the PHB polymerase gene ( $p h b C)$. J. Biol. Chem. 264: 15298-15303.

Peoples O.P., Sinskey A.J. (1989b) Poly-beta-hydroxybutyrate biosynthesis in Alcaligenes eutrophus H16. Characterization of the genes encoding beta-ketothiolase and acetoacetyl-CoA reductase. J. Biol. Chem. 264: 15293-15297.

Peters V., Becher D., Rehm B.H. (2007) The inherent property of polyhydroxyalkanoate synthase to form spherical PHA granules at the cell poles: the core region is required for polarlocalization. J. Biotechnol. 132: 238-245.

Pfeiffer D., Wahl A., Jendrossek D. (2011) Identification of a multifunctional protein, PhaM, that determines number, surface to volume ratio, subcellular localization and distribution to daughter cells of poly(3-hydroxybutyrate), PHB, granules in Ralstonia eutropha H16. Mol. Microbiol. 82: 936-951.

Philip S., Keshavarz T., Roy I. (2007) Polyhydroxyalkanoates: biodegradable polymers with a range of applications. J. Chem. Technol. Biotechnol. 82: 233-247. 
Potter M., Muller H., Reinecke F., Wieczorek R., Fricke F., Bowien B., Friedrich B., Steinbuchel A. (2004) The complex structure of polyhydroxybutyrate (PHB) granules: four orthologous and paralogous phasins occur in Ralstonia eutropha. Microbiology. 150: 2301-2311.

Qi Q., Rehm B.H., Steinbuchel A. (1997) Synthesis of poly(3-hydroxyalkanoates) in Escherichia coli expressing the PHA synthase gene phaC2 from Pseudomonas aeruginosa: comparison of PhaC1 and PhaC2. FEMS Microbiol. Lett. 157: 155-162.

Qi Q., Steinbuchel A., Rehm B.H. (2000) In vitro synthesis of poly(3-hydroxydecanoate): purification and enzymatic characterization of type II polyhydroxyalkanoate synthases PhaCl and PhaC2 from Pseudomonas aeruginosa. Appl. Microbiol. Biotechnol. 54: 37-43.

Rehm B.H., Kruger N., Steinbuchel A. (1998) A new metabolic link between fatty acid de novo synthesis and polyhydroxyalkanoic acid synthesis. The PHAG gene from Pseudomonas putida KT2440 encodes a 3-hydroxyacyl-acyl carrier protein-coenzyme a transferase. J. Biol. Chem. 273: 24044-24051.

Rehm B.H., Mitsky T.A. Steinbuchel A. (2001) Role of fatty acid de novo biosynthesis in polyhydroxyalkanoic acid (PHA) and rhamnolipid synthesis by pseudomonads: establishment of the transacylase (PhaG)-mediated pathway for PHA biosynthesis in Escherichia coli. Appl. Environ. Microbiol. 67: 3102-3109.

Rehm B.H., Antonio R.V., Spiekermann P., Amara A.A., Steinbuchel A. (2002) Molecular characterization of the poly(3-hydroxybutyrate) (PHB) synthase from Ralstonia eutropha: in vitro evolution, site-specific mutagenesis and development of a PHB synthase protein model. Biochim. Biophys. Acta. 1594: 178-190.

Rehm B.H. (2003) Polyester synthases: natural catalysts for plastics. Biochem. J. 376: 15-33.

Ritchie G.A., Senior P.J., Dawes E.A. (1971) The purification and characterization of acetoacetylcoenzyme A reductase from Azotobacter beijerinckii. Biochem. J. 121: 309-316.

Saegusa H., Shiraki M., Kanai C., Saito T. (2001) Cloning of an intracellular Poly[D(-)-3Hydroxybutyrate] depolymerase gene from Ralstonia eutropha H16 and characterization of the gene product. J. Bacteriol. 183: 94-100.

Saito T., Fukui T., Ikeda F., Tanaka Y., Tomita K. (1977) An NADP-linked acetoacetyl CoA reductase from Zoogloea ramigera. Arch. Microbiol. 114: 211-217.

Sato S., Kanazawa H., Tsuge T. (2011) Expression and characterization of (R)-specific enoyl coenzyme A hydratases making a channeling route to polyhydroxyalkanoate biosynthesis in Pseudomonas putida. Appl. Microbiol. Biotechnol. 90: 951-959.

Shinohe T., Nojiri M., Saito T., Stanislawski T., Jendrossek D. (1996) Determination of the active sites serine of the poly (3-hydroxybutyrate) depolymerases of Pseudomonas lemoignei (PhaZ5) and of Alcaligenes faecalis. FEMS Microbiol. Lett. 141: 103-109.

Shishatskaya E.I., Volova T.G., Efremov S.N., Puzyr' A.P., Mogil'naya O. A. (2002) Tissue response to biodegradable suture threads made of polyhydroxyalkanoates. Biomed. Eng. 36: 210-217.

Shishatskaya E.I., Volova T.G. (2004) A comparative investigation of biodegradable polyhydroxyalkanoate films as matrices for in vitro cell cultures. J. Mater. Sci. Mater. Med. 15: 915923.

Shishatskaya E.I., Voinova O.N., Goreva A.V., Mogilnaya O.A., Volova T.G. (2008) Biocompatibility of polyhydroxybutyrate microspheres: in vitro and in vivo evaluation. J. Mater. Sci. Mater. Med. 19: 2493-2502. 
Shishatskaya E.I., Goreva A.V., Voinova O.N., Kalacheva G.S., Volova T.G. (2009) Distribution and resorption of polymeric microparticles in visceral organs of laboratory animals after intravenous injection. J. Siberian. Fed. Univ. Biology. 4: 453-465.

Shozui F., Matsumoto K., Sasaki T., Taguchi S. (2009) Engineering of polyhydroxyalkanoate synthase by Ser477X/Gln481X saturation mutagenesis for efficient production of 3-hydroxybutyratebased copolyesters. Appl. Microbiol.Biotechnol. 84: 1117-1124.

Sim S.J., Snell K.D., Hogan S.A., Stubbe J., Rha C., Sinskey A.J. (1997) PHA synthase activity controls the molecular weight and polydispersity of polyhydroxybutyrate in vivo. Nat. Biotechnol. 15: 63-67.

Slater S., Houmiel K.L., Tran M., Mitsky T.A., Taylor N.B., Padgette S.R., Gruys K.J. (1998) Multiple beta-ketothiolases mediate poly(beta -hydroxyalkanoate) copolymer synthesis in Ralstonia eutropha. J. Bacteriol. 180: 1979-1987.

Stubbe J., Tian J., He A., Sinskey A.J., Lawrence A.G., Liu P. (2005) Nontemplate-dependent polymerization processes: polyhydroxyalkanoate synthases as a paradigm. Annu. Rev. Biochem. 74: 433-480.

Sudesh K., Abe H., Doi Y. (2000) Synthesis, structure, and properties of polyhydroxyalkanoates: biological polyesters. Prog. Polymer Sci. 25: 1503-1555.

Taguchi S., Maehara A., Takase K., Nakahara M., Nakamura H., Doi Y. (2001) Analysis of mutational effects of a polyhydroxybutyrate (PHB) polymerase on bacterial PHB accumulation using an in vivo assay system. FEMS Microbiol. Lett. 198: 65-71.

Taguchi S., Yamada M., Matsumoto K. \& others (2008). A microbial factory for lactate-based polyesters using a lactate-polymerizing enzyme. Proc. Natl. Acad. Sci. USA. 105: 17323-17327.

Thompson S., Mayerl F., Peoples O.P., Masamune S., Sinskey A.J., Walsh C.T. (1989) Mechanistic studies on beta-ketoacyl thiolase from Zoogloea ramigera: identification of the active-site nucleophile as Cys89, its mutation to Ser89, and kinetic and thermodynamic characterization of wild-type and mutant enzymes. Biochemistry. 28: 5735-5742.

Tian J., He A., Lawrence A.G., Liu P., Watson N., Sinskey A.J., Stubbe J. (2005a) Analysis of transient polyhydroxybutyrate production in Wautersia eutropha $\mathrm{H} 16$ by quantitative Western analysis and transmission electron microscopy. J. Bacteriol. 187: 3825-3832.

Tian J., Sinskey A.J., Stubbe J. (2005b) Kinetic studies of polyhydroxybutyrate granule formation in Wautersia eutropha H16 by transmission electron microscopy. J. Bacteriol. 187: 3814-3824.

Timm A., Steinbuchel A. (1990) Formation of polyesters consisting of medium-chain length 3-hydroxyalkanoic acids from gluconate by Pseudomonas aeruginosa and other fluorescent pseudomonads. Appl. Environ. Microbiol. 56: 3360-3367.

Timm A., Steinbuchel A. (1992) Cloning and molecular analysis of the poly(3-hydroxyalkanoic acid) gene locus of Pseudomonas aeruginosa PAO1. Eur. J. Biochem. 209: 15-30.

Tsuge T., Fukui T., Matsusaki H., Taguchi S., Kobayashi G., Ishizaki A., Doi Y. (2000) Molecular cloning of two (R)-specific enoyl-CoA hydratase genes from Pseudomonas aeruginosa and their use for polyhydroxyalkanoate synthesis. FEMS Microbiol. Lett. 184: 193-198.

Tsuge T., Taguchi K., Seiichi T., Doi Y. (2003) Molecular characterization and properties of (R)-specific enoyl-CoA hydratases from Pseudomonas aeruginosa: metabolic tools for synthesis of polyhydroxyalkanoates via fatty acid beta-oxidation. Int. J. Biol. Macromol. 31: 195-205. 
Tsuge T., Saito Y., Kikkawa Y., Hiraishi T., Doi Y. (2004) Biosynthesis and compositional regulation of poly[(3-hydroxybutyrate)-co-(3-hydroxyhexanoate)] in recombinant Ralstonia eutropha expressing mutated polyhydroxyalkanoate synthase genes. Macromol. Biosci. 4: 238-242.

Tsuge T., Watanabe S., Shimada D., Abe H., Doi Y., Taguchi S. (2007) Combination of N149S and D171G mutations in Aeromonas caviae polyhydroxyalkanoate synthase and impact on polyhydroxyalkanoate biosynthesis. FEMS Microbiol. Lett. 277: 217-222.

Uchino K., Saito T. (2006) Thiolysis of poly(3-hydroxybutyrate) with polyhydroxyalkanoate synthase from Ralstonia eutropha. J. Biochem. 139: 615-621.

Uchino K., Saito T., Gebauer B., Jendrossek D. (2007) Isolated poly(3-hydroxybutyrate) (PHB) granules are complex bacterial organelles catalyzing formation of PHB from acetyl coenzyme A (CoA) and degradation of PHB to acetyl-CoA. J. Bacteriol. 189: 8250-8256.

Uchino K., Saito T., Jendrossek D. (2008) Poly(3-hydroxybutyrate) (PHB) depolymerase PhaZa1 is involved in mobilization of accumulated PHB in Ralstonia eutropha H16. Appl. Environ. Microbiol. 74: 1058-1063.

Valentin H.E., Steinbuchel A. (1994) Application of enzymatically synthesized short-chain-length hydroxy fatty acid coenzyme A thioesters for assay of polyhydroxyalkanoic acid biosynthesis. Appl. Microbiol. Biotechnol. 40: 699-709.

Volova T.G., Kalacheva G.S., Trubachev I.N., Filippova V.K. (1987) The effect of physicochemical factors on growth and biochemical composition of carboxydobacteria. Microbiology (Rus). 57: 973978.

Volova T.G., Guseinov O.A., Kalacheva G.S., Medvedeva S.E., Puzyr A.P. (1988a) The effect of carbon monoxide on metabolism and structure of carboxydobacteria. Microbiology (Rus). 57: 793797.

Volova T.G., Kalacheva G.S., Trubachev I.N., Filippova V.K. (1988b) A study of physiological and biochemical parameters of carboxydobacteria limited by deficinecy of mineral elements. Microbiology (Rus). 57: 61-64.

Volova T.G., Kalacheva G.S., Altukhova O.V. (2001) Autotrophic synthesis of polyalkanoates by Alcaligenes eutrophus in the presence of carbon monoxide. Mikrobiologia. 70: 745-752.

Wakadkar S., Hermawan S., Jendrossek D., Papageorgiou A.C. (2010) The structure of PhaZ7 at atomic $(1.2 \mathrm{~A})$ resolution reveals details of the active site and suggests a substrate-binding mode. Acta Crystallogr. Sect. F. Struct. Biol. Cryst. Commun. 66: 648-654.

Wang H.H., Zhou X.R., Liu Q., Chen G.Q. (2011) Biosynthesis of polyhydroxyalkanoate homopolymers by Pseudomonas putida. Appl. Microbiol. Biotechnol. 89: 1497-1507.

Wang Q., Tappel R.C., Zhu C., Nomura C.T. (2012) Development of a new strategy for production of medium-chain-length polyhydroxyalkanoates by recombinant Escherichia coli via inexpensive nonfatty acid feedstocks. Appl. Environ. Microbiol. 78: 519-527.

Yabutani T., Maehara A., Ueda S., Yamane T. (1995) Analysis of beta-ketothiolase and acetoacetylCoA reductase genes of a methylotrophic bacterium, Paracoccus denitrificans, and their expression in Escherichia coli. FEMS Microbiol. Lett. 133: 85-90.

York G.M., Lupberger J., Tian J., Lawrence A.G., Stubbe J., Sinskey A.J. (2003) Ralstonia eutropha H16 encodes two and possibly three intracellular Poly[D-(-)-3-954 hydroxybutyrate] depolymerase genes. J. Bacteriol. 185: 3788-3794. 
Yuan W., Jia Y., Tian J., Snell K.D., Muh U., Sinskey A.J., Lambalot R.H., Walsh C.T., Stubbe J. (2001) Class I and III polyhydroxyalkanoate synthases from Ralstonia eutropha and Allochromatium vinosum: characterization and substrate specificity studies. Arch. Biochem. Biophys. 394: 87-98.

Zheng L.Z., Li Z., Tian H.L., Li M., Chen G.Q. (2005) Molecular cloning and functional analysis of (R)-3-hydroxyacyl-acyl carrier protein:coenzyme A transacylase from Pseudomonas mendocina LZ. FEMS Microbiol. Lett. 252: 299-307.

Zheng Z., Zhang M.J., Zhang G., Chen G.Q. (2004) Production of 3-hydroxydecanoic acid by recombinant Escherichia coli HB101 harboring phaG gene. Antonie Van Leeuwenhoek. 85: 93-101.

\title{
Ферменты, участвующие в синтезе \\ полигидроксиалканоатов: \\ обзор и биологическая перспектива
}

\author{
К.Д. Бригам ${ }^{\mathrm{a}}$ Э.Д. Сински ${ }^{\mathrm{a}, \overline{0}, \mathrm{~B}, \mathrm{r}}$ \\ a Отделение биологии, \\ Массачусетский технологический институт, \\ Кембридж, Массачусетс 02139, США \\ ${ }^{\sigma}$ Сибирский федеральный университет, \\ Россия 660041, Красноярск, пр. Свободный, 79 \\ ${ }^{\circ}$ Отдел инженерных систем, \\ Массачусетский технологический институт, \\ Кембридж, Массачусетс 02139, США \\ ' Отдел технологии медицинь, \\ Массачусетский технологический институт, \\ Кембридж, Массачусетс 02139, США
}

Интерес к полигидроксиалканоатам (ПГА) вызван тем, что они являются биодеградируемыми биосовместимыми полимерами на биологической основе. Учёные накопили широкий спектр знаний о процессе биосинтеза этих ценных полимеров; специалисты в таких областях, как микробиология, биохимия, физика, медицина и технология, внесли свой вклад в современное состояние знаний о синтезе, получении и применении ПГА. Важное значение для перспектив биосинтеза ПГА имеет группа микробных ферментов, которые участвуют в производстве ПГА и их многочисленных разновидностей. В этом обзоре мы рассматриваем ключевые ферменты синтеза и гомеостаза всех типов ПГА. Особое внимание уделяется структуре и функиионированию ферментов и тому, как энзимология сформировала знания о пути создания ПГА и известила о новых открытиях.

Ключевые слова: биопластики, полигидроксиалканоат, ферменты, гранулосвязанные белки, биосинтез полимера, гомеостаз ПГА. 